\title{
Guest Editorial: Fire Safety in Mines
}

\author{
Charles D. Litton*, Office of Mine Safety and Health Research, National \\ Institute for Occupational Safety and Health, 626 Cochrans Mill Road, PO \\ Box 18070, Pittsburgh, PA 15236, USA
}

Received: 13 November 2014/Accepted: 14 November 2014

Fires in underground mines pose unique problems typically not encountered in other industries. The underground tunnels and entries may be lined with coal or heavily laden with wood for support providing an almost endless supply of fuel while the forced ventilation airflow provides a constant supply of oxygen to fuel the fires that occur while, at the same time, transporting smoke and toxic gases to distances far-removed from the affected fire area. Other fuels exist such as conveyor belts or liquid diesel fuel that may also contribute to the overall fire hazard if consumed as part of a spreading fire. Fires in mines may often be of spontaneous origin when coal is oxidized resulting in self-heating and a smoldering fire that is difficult to prevent and to control. To address these types of fires, Pandey et al. [1] describe the development of chemical retardants that can inhibit, if not prevent, the oxidation and subsequent self-heating of coal. Regardless of the type of fire or combustibles involved, escape-ways and means of egress are often limited placing a high burden on early detection and warning systems in order to rapidly start the evacuation and control measures when fire prevention techniques have not been successful. Understanding the characteristics of the smoke and toxic gases produced can aid in the development of better detection and monitoring systems as well as provide a better understanding of the hazards of toxicity and obscuration that mine fires produce. To aid in this understanding, Perera and Litton [2] discuss the results of experiments to define and quantify the physical and optical properties of aerosols produced from both smoldering and flaming fires from a variety of combustible mine materials.

When preventive and detection measures are unsuccessful and the resultant large fires cannot be extinguished locally and burn out of control, the common technique in mines is to seal portions of the underground mine and let the fire consume the available oxygen, eventually self-extinguishing. But in underground coal mines, this practice may produce additional problems due to the liberation of methane from the coal strata and while methane/air mixtures in normal air have well-recognized flammability limits, in sealed areas with a depleting supply of oxygen, determining these limits is not often straightforward. In instances such as these, developing techniques to assess the explosibility of the sealed atmosphere becomes of paramount importance. Eventually, when sealed fires are extinguished, the sealed area needs to be recovered and ventilation restored to the affected area.

\footnotetext{
* Correspondence should be addressed to: Charles D. Litton, E-mail: clitton@cdc.gov
} 
The decision of when to attempt recovery is usually guided by the results of gas analysis from the atmosphere of the sealed area but these analyses may often be confused by the presence of methane or imperfect sealing techniques that allow air leaks. As a result, determining the status of the fire is of major concern in order to prevent re-kindling of the fire or the exposure of explosive methane/air mixtures to the presence of hot, smoldering areas that can serve as ignition sources.

Five of the papers in this issue deal with these unique sealed fire problems. Ma and Larranaga [3] construct a diluted flammability diagram to assess flammability of gases in a reduced oxygen atmosphere while in Letter to the Editor, the same authors [4] develop the concept of a heating/quenching ratio to explore the explosibility of gases in a sealed area. Cheng and Zhou [5] expand upon the Coward explosibility technique to develop methods for inertization of explosive atmospheres while Cheng, Luo and Zhou [6] derive an explosibility safety factor that is an extension and enhancement of Coward's work in order to improve safety in the recovery of sealed areas. Fu-bao et al. [7] describe the use of liquid nitrogen infusion to extinguish sub-surface coal fires and enhance mine recovery operations.

The problems discussed in the papers that make up this issue serve to highlight some of the unique fire safety problems that confront the mining community. While these papers may explore problems that are unique, it must be noted that fire safety in mines also encompasses the same areas of detection, flammability, and suppression that are common to above-ground industries and that there exists on-going research to address these common problems as well.

\section{References}

1. Pandey J, Mohalik NK, Mishra RK, Khalkho A, Kumar D, Singh VK (2014) Investigation of the role of fire retardants in preventing spontaneous heating of coal and controlling coal mine fires. Fire Technol. doi:10.1007/s10694-012-0302-9

2. Perera IE, Litton CD (2014) Quantification of optical and physical properties of combustion-generated carbonaceous aerosols $\left(<\mathrm{PM}_{2.5}\right)$ using analytical and microscopic techniques. Fire Technol. doi:10.1007/s10694-013-0376-z

3. Ma T, Larrañaga M (2014) Theoretical flammability diagram for analyzing mine gases. Fire Technol. doi:10.1007/s10694-013-0355-4

4. Ma T, Larrañaga MD (2014) Proposing a progress variable for monitoring compartment backdrafts and coal mine fires. Fire Technol. doi:10.1007/s10694-014-0417-2

5. Cheng J, Zhou F (2014) Revised explosibility diagram to judge best practice of controlling an explosive gas-mixture. Fire Technol. doi:10.1007/s10694-014-0387-4

6. Cheng J, Luo Y, Zhou F (2014) Explosibility safety factor: an approach to assess mine gas explosion risk. Fire Technol. doi:10.1007/s10694-013-0324-y

7. Fu-bao Z, Bo-bo S, Jian-wei C, Ling-jun M (2014) A new approach to control a serious mine fire with using liquid nitrogen as extinguishing media. Fire Technol. doi:10.1007/ s10694-013-0351-8 